\title{
CINEMA AMERÍNDIO: SILÊNCIO E ESQUIVA EM TRADUÇÃO
}

\author{
Sabrina Alvernaz Silva Cabral ${ }^{1}$ \\ Sérgio Luiz Rodrigues Medeiros ${ }^{1}$ \\ ${ }^{1}$ Universidade Federal de Santa Catarina, Florianópolis, Santa Catarina, Brasil
}

Resumo: O presente artigo busca se aproximar da imaginação conceitual guarani por meio dos documentários "Tekoha - o som da terra" (2017) de Rodrigo Arajeju e Valdelice Veron e "Os verdadeiros líderes espirituais" (2013) de Alberto Alvares. Partimos do princípio de que a linguagem sonora e visual põe em diálogo cosmologias distintas (a ameríndia e a ocidental). O primeiro filme, que aborda a grave crise humanitária vigente nas reservas e áreas de retomada enfrentada pelo povo kaiowá no Mato Grosso do Sul, oportuniza a discussão sobre como a linguagem cinematográfica funciona nesta obra para expressar o luto e a luta desse povo. $\mathrm{O}$ segundo filme, que versa sobre o modo de ser guarani (nhande reko) a partir dos conhecimentos do xeramõi Alcindo e xejarji Rosa, em aldeia de Santa Catarina, abre ocasião para refletir como o silêncio e a esquiva constituem uma invisibilidade estratégica guarani.

Palavras-chave: Documentário; Cinema Indígena; Tradução; Cosmologia Guarani

\section{AMERIDIAN CINEMA: SILENCE AND AVOIDANCE IN TRANSLATION}

\begin{abstract}
This article approaches Guarani indigenous people's conceptual imagination through the documentaries "Tekoha - o som da terra" (2017) of Rodrigo Arajeju and Valdelice Veron and "Os verdadeiros líderes espirituais" (2013) of Alberto Alvares. We started from the sound and visual language put different cosmologies (Indigenous and Western) in dialogue. The first film, which addresses the serious humanitarian crisis in the reserves and areas of resumption faced by the Kaiowá people in Mato
\end{abstract}


Grosso do Sul, provides an opportunity to discuss how cinematographic language works in this work to express the mourning and struggle of these people. The second film, which deals with the Guarani way of being (nhande reko) based on the knowledge of the xeramõi Alcindo and xejarji Rosa, in Santa Catarina, opens the occasion to consider how silence and avoidance constitute Guarani's strategic invisibility.

Keywords: Documentary; Indigenous Cinema; Translation; Guarani Cosmology

\section{Introdução}

Como falar sobre um povo ameríndio? Para um povo ameríndio? Com um povo ameríndio? Pensar o cinema por meio da tradução é resgatar nos jogos tradutórios os princípios das omissões e das criações, das dúvidas e dos questionamentos, das resistências e das renúncias, dos atritos e das surpresas que estão pressupostos na tarefa do tradutor. Desdobrar uma linguagem sonora e visual que dê conta de colocar ontologias distintas (ameríndia e ocidental) em diálogo é um labor semelhante ao que o tradutor encontra diante da reimaginação de um texto poético, por exemplo. Pôr em ação o que outrora funcionara em outra língua é fazer fluir aquele modo de vida nesse outro espaço-tempo da tradução. Transferir para o enquadramento da tela um saber é arriscar-se a experimentar outro espaço-tempo do cinema.

O gesto tradutório, como sabemos, pressupõe um texto de partida e outro de chegada, um texto fonte e outro meta. O cinema aqui imaginado como o que aciona uma tradução se constitui da transformação do argumento em linguagem audio-visual, da palavra transformada em imagem e som. Partimos ainda da ideia de que quando um indígena, por meio da câmera, constrói uma narrativa cinematográfica, nasce um jogo que exige tradução entre cosmologias distintas: esse encontro comparece na própria feitura dos filmes que, de modo geral, requer um saber cruzado entre indígenas e não-indígenas, bem como na recepção desses filmes que inclui interlocutores tão díspares. 
Essa disparidade epistemológica que se manifesta no público que vive a cosmologia ameríndia ou não-ameríndia não deve ser vista como um entrave na recepção fílmica. A esse respeito, o ensinamento benjaminiano de que uma obra de arte não pode idealizar seu interlocutor nos é proveitoso. Em suas palavras:

O próprio conceito de um receptor 'ideal' é nefasto em quaisquer indagações de caráter estético, porque estas devem pressupor unicamente a existência e a essência do homem em geral. Da mesma forma, também a arte pressupõe a essência corporal e espiritual do homem; mas, em nenhuma de suas obras, pressupõe sua atenção. Nenhum poema dirige-se, pois, ao leitor, nenhum quadro, ao espectador, nenhuma sinfonia, aos ouvintes (Benjamin 203).

Existe, em alguma medida, um desastre ao se imaginar um "homem em geral" enquanto interlocutor - algo que a indústria cultural se esmera por fazer, como nos ensina Adorno. Este trabalho, entretanto, não se interessa pela "cultura de massa", para ficarmos com o termos adornianos, mas pela linguagem dos documentários "Tekoha - o som da terra" ${ }^{1}$ (2017, 20min) de Rodrigo Arajeju e Valdelice Veron e "Os verdadeiros líderes espirituais"² (2013, 67 min) de Alberto Álvares.

Vamos nos deter na discussão de signos cinematográficos enquanto capazes de traduzir aquilo que para um povo é sabidamente importante e junto com isso o que de tão intrínseco nem lhe é percebido. Eis alguns dos desafios do documentário e deste artigo.

${ }^{1}$ Disponível em link privativo: https://vimeo.com/217334549 (senha: TEKOHA).

${ }^{2}$ Disponível em: https://www.youtube.com/watch?v=mpNAxnL45UM.

Cad. Trad., Florianópolis, v. 41, no 2 p. 328-361, mai-ago, 2021. 


\section{A demarcação da tela}

O filme "Tekoha - o som da terra" (2017, 20min) é fruto de uma pesquisa-intervenção realizada por Rodrigo Ferreira (cujo nome guarani é Arajeju) no Tekoha Takuara, localizado no Mato Grosso do Sul (MS), num processo intercultural colaborativo com lideranças femininas em território de retomada do Povo Kaiowa, em especial, com a liderança Valdelice Veron que integra roteiro, direção e montagem. Assim Arejeju define seus propósitos:

[neste documentário] abordei a grave crise humanitária vigente nas reservas e áreas de retomada, a omissão do Estado brasileiro na demarcação das terras reivindicadas, a insustentabilidade do desenvolvimento do agronegócio no estado e a escalada da violência étnica - denunciada pelos representates do Conselho Aty Guasu como genocídio. $\mathrm{O}$ tema central é a liderança das nhandesy (pronuncia-se nhandessú), enquanto matriarcas e guias espirituais, por meio do exercício dos processos autogestionários da vida e do território na retomada do Tekoha Takuara (Ferreira 3).

A palavra em guarani tekoha, de difícil tradução, recebe especial atenção, no trabalho acadêmico desenvolvido por Arajeju, rumo à tentativa de trazer luz aos seus sentidos mais intrínsecos. Ao termo tekoha, que deriva de conceitos cosmológicos para expressar a representação dos territórios, não caberia a simplista tradução como "terra em que se vive", tendo em vista que são "espaços determinantes para o modo de ser e viver (nhande reko) do Povo kaiowa e guarani” (Ferreira 3).

tekoha, deve ser apreendida como uma categoria nativa polissêmica central no sistema cultural kaiowá e que, nas circunstâncias históricas atuais, é expressa fundamentalmente como o lugar (território), no qual uma comunidade kaiowá (grupo social composto por diversas parentelas) 
vive de acordo com sua organização social e seu sistema cultural (cultura). A compreensão do sentido atribuído pelas comunidades kaiowá atuais ao tekoha deve levar em consideração as transformações históricas ocorridas a partir da segunda metade do século passado, quando a falta de terras se tornou, para a maioria das comunidades kaiowá, entrave para a reprodução do sistema social kaiowá (Ferreira 5).

Dessa forma, opta-se por manter no título do documentário e em seu discurso interno o termo tekoha sem sua respectiva tradução. O sentido dessa palavra é visto como "um lugar de costume e de modo de vida", que é produto da cultura e também produz cultura - o que demonstra uma profunda relação entre vida, modo de vida e território.

Nos filmes anteriores de Arajeju "Índios no poder" (2014, 52min) e "Índios cidadãos?" (2015, 21 min), já era possível entrever um pacto entre o cineasta e a luta indígena. Os documentários se constituem enquanto voz capaz de descrever, a partir de entrevistas, registros documentais e imagens de arquivo, o movimento dos povos originários no Congresso Nacional (Ferreira 35). Nesse contexto, os dois documentários quase se aproximam de "manifestos" ou "petições audiovisuais" que denunciam contradições em relação à política indigenista.

Porém, se os dois filmes anteriores estão ligados intrinsecamente pela proximidade de seu estilo e de sua temática, o último documentário de Arajeju imbui-se de criar outra linguagem cinematográfica. Pontuamos, por exemplo, que a palavra verbalizada, a narrativa off, só começa decorridos os cinco minutos iniciais do documentário, já pré-anunciando a importância do silêncio ao longo do filme. As imagens cuidadosamente capturadas substituirão o discurso explicativo feito diretamente para a câmera que compõe, por exemplo, "Índio Cidadão?".

As escolhas fílmicas de "Tekoha - o som da terra" destacamse enquanto potência: o silêncio, o ritmo, os planos longos com 
expressiva profundidade de campo, os jogos de luz costuram uma textura, que aqui nomeamos de poética ${ }^{3}$.

Por "poesia", tomamos emprestada a concepção de Marjorie Perloff ao ler Wittgenstein "o poético funciona assim como uma forma elevada de crítica social e cultural, um modo de desautomatização não tanto do que é visto [...] mas do que é conhecido e realmente feito" (Perloff 230) ou, ainda, "a poesia não é 'a expressão ou a exteriorização de um sentimento interno; é mais precisamente, a crítica dessa expressão' (Perloff 226). Em outras palavras, o poético ao preocupar-se menos com o registro de palavras ou imagens, expõe, em outro sentido, uma leitura, uma crítica a partir de um lugar desacostumado.

Segundo Jerome Rothenberg, em "Etnologia no Milênio", reconhece-se que "Muitos poemas indígenas prescindem completamente de palavras", mas outros elementos farão sua vez como "música, sons fonéticos não verbais, dança, gesto e evento, jogo, sonho" (Rothenberg 74) e, acrescentamos, obras cinematográficas.

É, portanto, por meio do reconhecimento da liberdade que o poema possui em relação à palavra que Rothenberg discute a percepção do que é um poema, “é tudo o que acontece: e se é assim, insistir que ele é apenas uma parte (palavras), significa interpretá-lo erroneamente, e perder a totalidade da sua presença" (Rothenberg 92); ao mesmo tempo que critica a ideologia colonialista, que faz das narrativas gregas e hebraicas o berço do mundo. A esse respeito, o ensaísta defende:

3 Para construir uma comparação, citamos o trabalho de Julio Plaza que, em "Tradução Intersemiótica", concebe os filmes como uma tradução icônica. Neste livro, o artista e teórico se detém, dentre outros, no filme "Encouraçado Potemkin" (1929) de Serguei Einstein para discutir a "montagem como escrita cultural", a montagem expressiva. Para isso, considera o argumento narrativo organizado em atos e sua tradução fílmica. O argumento que, segundo Plaza, está condensado na ideia da "organicidade progressiva do processo revolucionário" (Plaza 138) encontrará na montagem sua metáfora. É, portanto, por meio da linguagem cinematográfica enquanto tradução que Plaza lê os efeitos da câmera e da montagem. 
Era importante que 'se evitasse uma definição fechada e europeia de 'poema' e trabalhasse empiricamente ou por analogia a experimentos contemporâneos, destruidores de limites (como a poesia concreta, poesia sonora, intermídia, happenings. Uma vez que a poesia tribal era quase sempre parte de uma situação maior (i.e., era verdadeiramente intermídia) já não havia nenhuma razão para apresentar só as palavras como estruturas independentes do que os eventos de ritual, digamos, ou os pictogramas que surgiram da mesma fonte' (Rothenberg 76).

Destacamos, então, o jogo poético que compõe o filme, recorrentemente construído em contraste ${ }^{4}$ : as árvores em contraponto com o desmatado, o trator a fantasmagorizar o canto superior direito da tela e o yvyra' $i$ (traduzido como altar) a demarcar o canto esquerdo, o preto e o branco (Imagem 1).

A presença da floresta na terra ocupada pelo povo kaiowa aponta para um modo de vida que concebe a terra como um parente, como "alguém" que goza de direitos e que não pode deixar de existir. Na cosmologia ameríndia, o planeta não é concebido como nave em que se habita, como ensinou a tradição kantiana, na medida em que o homem é natureza ${ }^{5}$. Em contraponto, salta aos olhos o desmatado, que remete a monocultura do velho sistema colonial brasileiro de desigualdade e de destruição. O trator, por sua vez, quando aparece, ratifica o agronegócio que expulsa e mata o povo kaiowa. O que com ele está em contraste na tela é o yvyra'i, metonímia da religiosidade guarani.

\footnotetext{
${ }^{4}$ Ainda sobre o efeito que o contraste pode construir, Julio Plaza afirma que "o conflito entre dois elementos opostos e antagônicos faz explodir o campo visual, dilatando e contraindo o espaço, concretizando-o, criando, assim, uma diferença visualmente dinâmica. Em todas as artes o contraste é uma poderosa ferramenta de expressão, um meio para intensificar o significado e, portanto sintetizar a comunicação. O contraste funciona, como tal, em conflito com seu oposto: a harmonia. Esse par dialógico estimula e atrai a atenção na comunicação visual" (Plaza 143)

${ }^{5}$ Mais a esse respeito em "A queda do céu" (Kopenawa, Davi; Albert, Albert) e "Pachamama e o ser humano" (Zaffaroni, Raúl).
} 
Figura 1: Tekoha

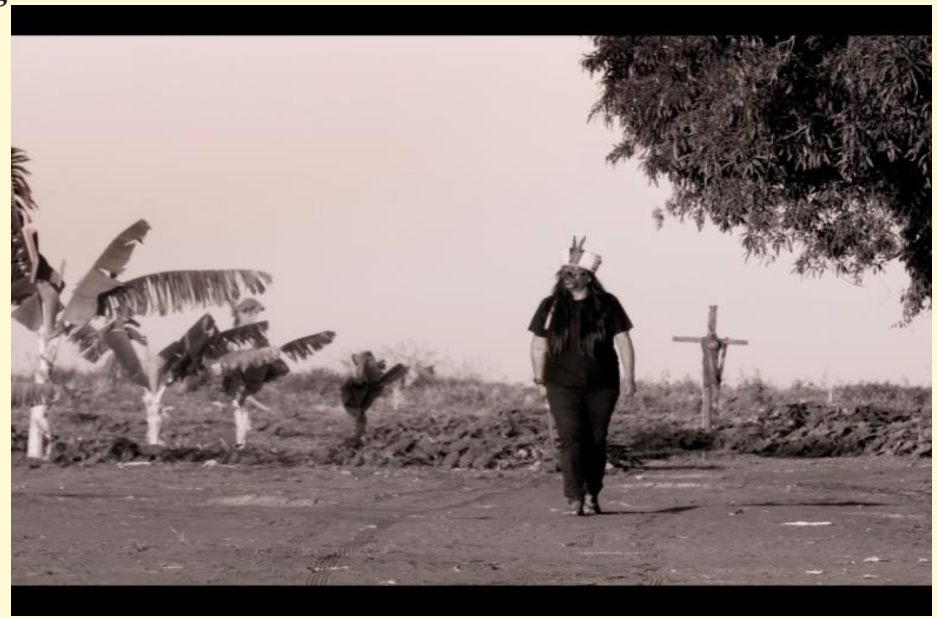

Fonte: o som da terra, 2017.

Esse jogo com opostos também é posto nas vestimentas. Valdelice usa preto, quando carrega um facão e reafirma, dessa forma, tanto seu luto quanto seu espírito guerreiro (Imagem 2). Ao mesmo tempo, nas cenas em que constrói o cotidiano com sua família, sua rotina ou seu rito, ela veste o poty branco - vestido de algodão adornado com símbolos culturais, como na cena em que as personagens Julia, Valdelice e Arami Veron tomam mate ou fabricam suas roupas (Imagens 3 e 4).

Cabe trazer a tona que essa sequência em que costuram o poty é composta de diálogos, mas essas falas não são traduzidas. De acordo com Rodrigo Arajeju, o objetivo era evitar a dispersão com a legenda e "aproveitar ao máximo os elementos visuais" (Ferreira 31). Para nós, contudo, o efeito gerado é potencializado pela criação de certa interdição. Ao impedir que o interlocutor que não domina a língua guarani acesse aquele momento, sugere-se certa impossibilidade de adentrar naquele universo íntimo compartilhado em família, naquela cosmologia guarani não compreendida pelos de fora. 
A sugestão de que não é qualquer pessoa que adentra esse pensamento-espaço-tempo se revela, por exemplo, quando Rodrigo Arajeju só consegue autorização do povo guarani kaiowá para produzir o filme, após os espíritos indicarem sua aprovação em sonhos para o xamã. Logo em seguida, recebe o nome guarani em ritual indígena "Arajeju" que em tradução literal significa "parente". Só, depois disso, o cineasta poderia traduzir em filme a luta kaiowa.

Figura 2: Tekoha

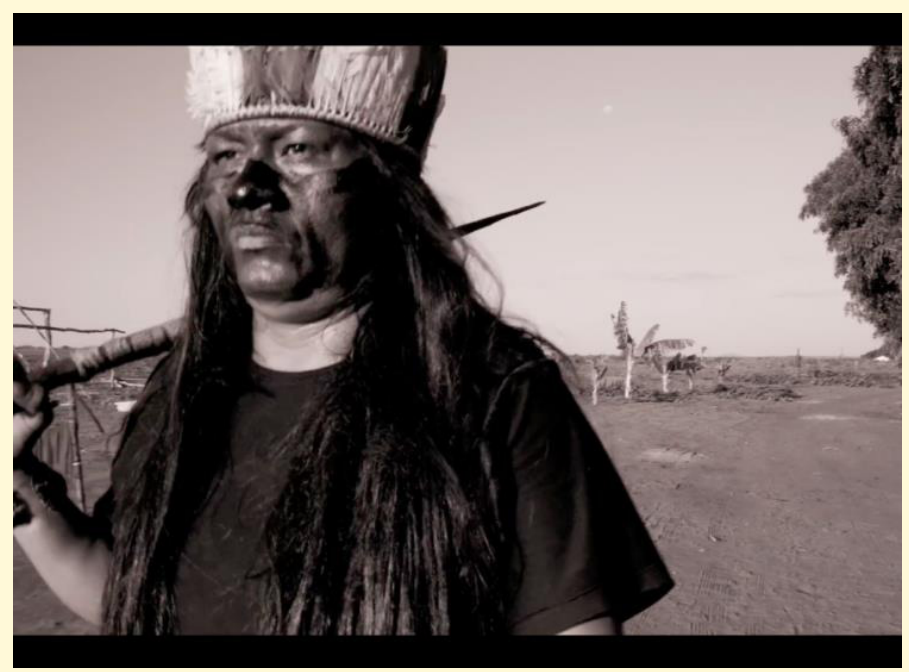

Fonte: o som da terra, 2017. 
Figura 3: Tekoha

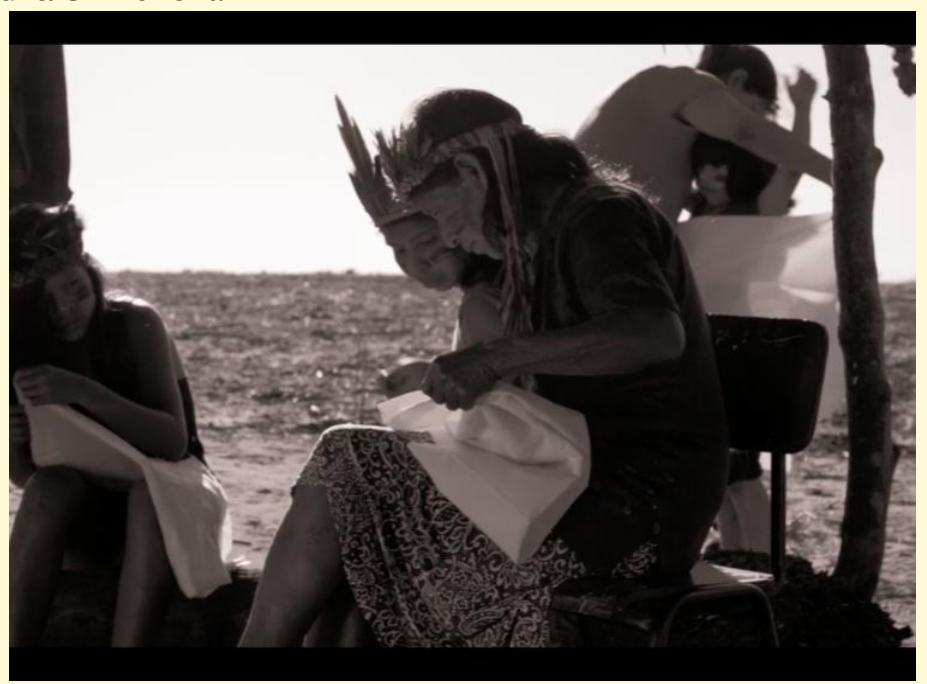

Fonte: o som da terra, 2017.

Figura 4: Tekoha

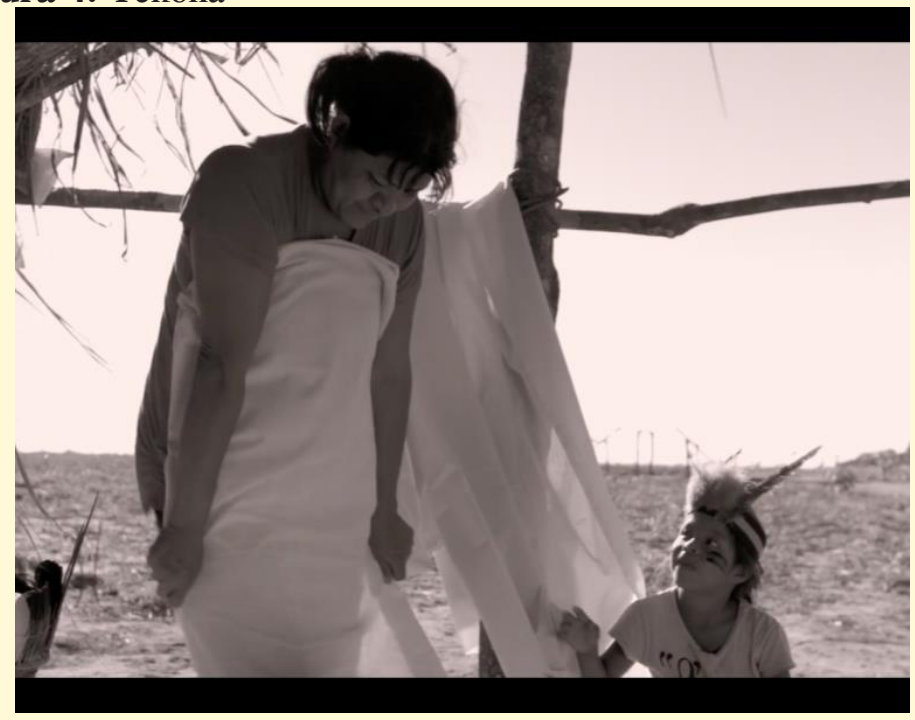

Fonte: o som da terra, 2017. 
Descrevemos, a seguir, algumas peculiaridades fílmicas que para nós são relevantes em "Tekoha - o som da terra": primeiramente, abordamos o jogo de luz que permeia o documentário, em seguida, consideramos o uso produtivo de plano-sequência ${ }^{6}$ longo, com profundidade de campo.

A escolha pela ausência de cores, entendida como um símbolo de luto ${ }^{7}$, dialogará com o jogo de luz que forja simbolismos importantes para a compreensão da cosmologia guarani. Citamos dois exemplos.

O primeiro se dá quando a matriarca entra na mata acompanhada do maracá e do canto religioso (Imagem 5). A luz que atravessa as copas das árvores iluminará seu gesto ancestral, insinuando pela claridade a relevância de tal ato. Em "A fala sagrada: mitos e cantos sagrados dos índios guarani”, Pierre Clastres nos ensina que é "a sua religiosidade que anima seu espírito de resistência" (Clastres 11) e ainda "poucos povos testemunham uma religiosidade tão intensamente vivida, vínculos tão profundos aos cultos tradicionais" como o povo guarani (Clastres 10).

O segundo exemplo de jogo de luz é expresso na explosão do sol, para onde corre a pequena Arami, filha de Valdelice, que leva nas mãos o panambi (ou "a borboleta que voa atrás", que fora traduzido como "pipa"), (Imagem 6). Essa cena carrega uma potência - não é sem motivo que tal gesto abre e encerra o curta-metragem. A corrida guarda uma semente de esperança, de leveza. A menina

\footnotetext{
${ }^{6}$ Embora não seja nossa intenção teorizar quanto aos conceitos cinematográficos, pontuamos que o plano-sequência pode ser entendido como um longo plano sem cortes que efetivamente narra uma sucessão de acontecimentos, uma "unidade narrativa equivalente a uma sequência", segundo Journot. Espera-se que a câmera desempenhe uma ação de movimento narrativo nessa sucessão de acontecimentos, não havendo a obrigatoriedade de ser ambientado em mais de um espaço. Disponível em: https://revistamoviement.net/24-planos-sequenciaedb70884c844.

7 "O tratamento em PB reforça a ideia de que o mundo tradicional Kaiowa, estritamente dependente das matas, está perdendo as cores da vida - o verde da vegetação, o vermelho do urucum, [o colorido] das penas dos pássaros para seus adornos sagrados como o jeguaka (cocar)" (Ferreira 21).
} 
está na sua terra sagrada, no seu tekoha. Ali pode correr e viver. O movimento também pode se constituir enquanto metáfora na medida em que uma das características marcantes do povo guarani é a migração em direção ao nascer ou pôr do $\mathrm{sol}^{8}$.

Com relação à escolha de planos longos em detrimento da montagem permeada de cortes acelerados, podemos afirmar que o efeito é a construção de um ritmo expressivo ao documentário. Num desses planos, Valdelice percorre o espaço, apenas caminhando sem nada dizer. Há neste gesto um demarcar não só a tela, mas metaforicamente também a terra (Imagem 7). Novamente, comparece a antítese entre o campo devastado e a floresta e o indicativo da morte.

Descreveremos, para exemplificar, uma cena em que a profundidade de campo agrega valor à narrativa: na primeira, está uma cruz à esquerda e a câmera alarga o campo de visão, abrindo um território devastado à direita (Imagem 8). Valdelice para e olha para cruz e campo, ambos concretizam a morte, imposta ao povo kaiowá, mas também à terra. A sepultura é de seu primo Virgílio, que se suicida após ter sofrido perseguições, prisão arbitrária e tortura (Ferreira 49).

O caminho do kurusu do cacique Marcos Veron ao de Virgílio representa a expansão da ocupação do território tradicional de 2003 até 2016. A sepultura do primo de Valdelice demarcou o local da última retomada, empreendida na data dedicada à memória de seu pai. $\mathrm{O}$ cacique Marcos Veron é mártir da luta do Tekoha Takuara e referência do movi-

\footnotetext{
${ }^{8}$ A esse respeito ver: "Trata-se das migrações religiosas que lançavam milhares de índios em busca apaixonada do paraíso terrestre, frequentemente do oeste para o leste, na direção do sol nascente, e às vezes no sentido inverso, na direção do sol poente" (Castres 11).

O termo em guarani “oguata porã" pode ser traduzido por "caminhadas sagradas". A mobilidade territorial é uma marca importante nessa cosmolodia: "são os lugares revelados e consolidados por intermédio dos antepassados, lideranças e xamãs em suas práticas do guata porã que possibilitam que os demais Guarani variem, cada qual ao seu modo, sua dinâmica nas diferentes tekoa existentes, produzindo uma mobilidade pessoal no território" (Keese 85).
} 
mento histórico de retomadas do Povo Kaiowa e Guarani no MS. No dia de seu funeral, em 2003, foram feitas diversas retomadas no estado, dada a comoção que o crime gerou entre o Povo (Ferreira 29).

O interlocutor iniciado na luta kaiowa fará pontes entre os dados históricos postos no documentário e os recorrentes casos de suicídio do povo kaiowa bem como o assassinato de importantes lideranças kaiowa, como a de Marco Veron que fora executado durante a retomada do Tekoha Takuara em janeiro de 2003, violência descrita por Valdelice em "Índio Cidadão?".

Figura 5: Tekoha

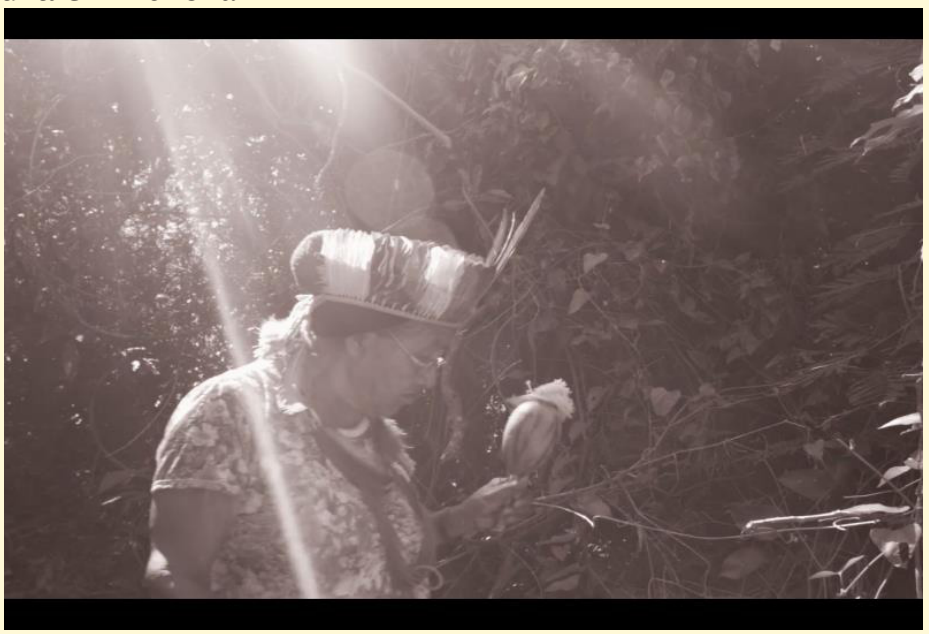

Fonte: o som da terra, 2017. 
Figura 6: Tekoha

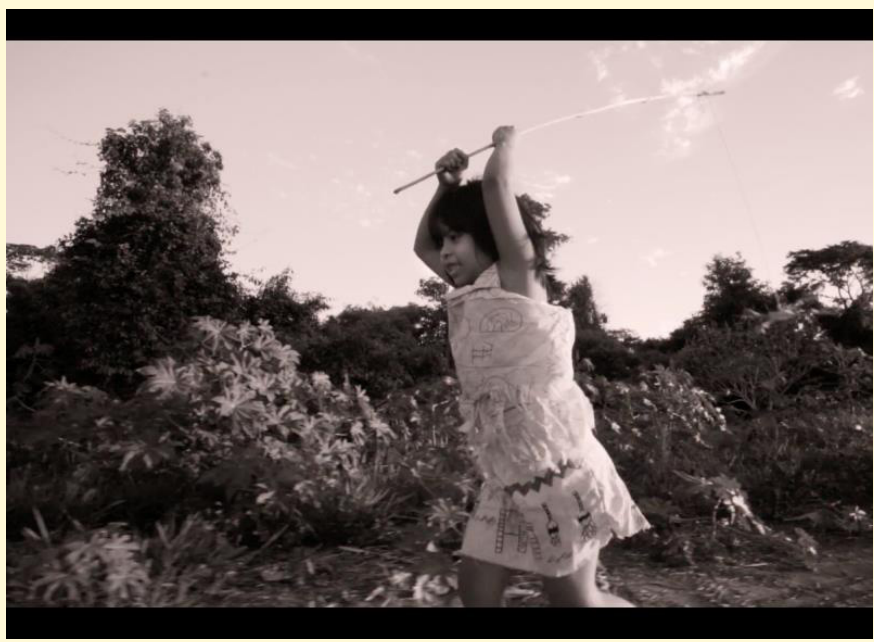

Fonte: o som da terra, 2017.

Figura 7: Tekoha

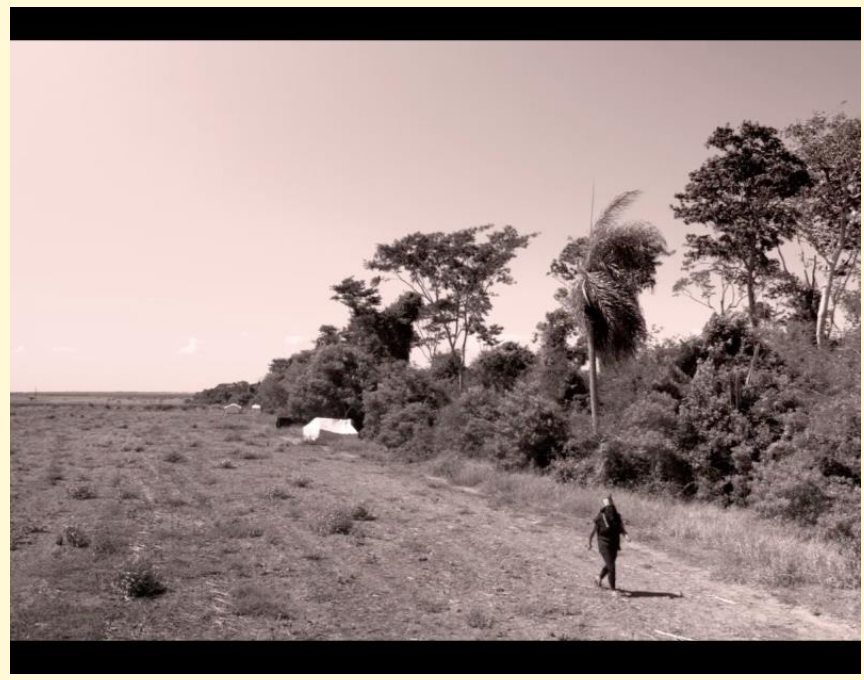

Fonte: o som da terra, 2017. 
Figura 8: Tekoha

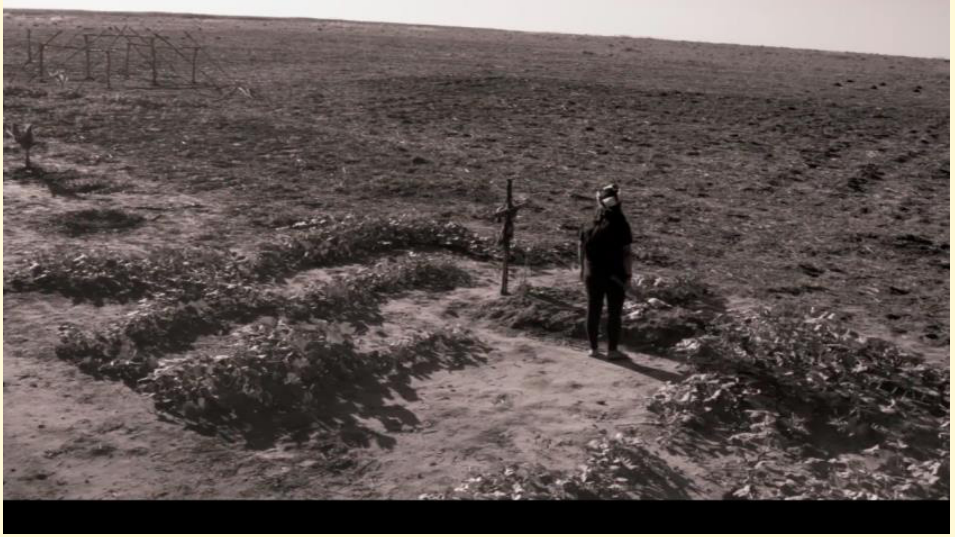

Fonte: o som da terra, 2017.

Destacamos que no processo de aliança para fabricação do filme, Rodrigo Arajeju e Valdelice Veron conciliaram diferentes visões de mundo para a composição do curta-metragem.

No processo de reflexão sobre a feitura cinematográfica, Arajeju descreve a influência conceitual kaiowá nas três etapas do projeto (pré-produção, produção e pós-produção), de modo a "moldar o conteúdo do filme-intervenção por meio da escolha dos conhecimentos tradicionais passiveis de serem mostrados e da definição da narrativa como estratégia de comunicação com o público não-indígena" (Ferreira 83, grifos nossos). Para exemplificarmos esse processo que também é tradutório, citamos o seguinte fragmento:

O primeiro corte do filme foi assistido com a nhandesy Julia, Valdelice e Arami, em junho de 2016, na cidade de Dourados [...] A partir de julho de 2016, Valdelice Veron participou, presencialmente, do processo de pós-produção, 
em Brasília, colaborando de forma relevante para a obtenção do resultado final do produto-intervenção. No primeiro momento, ela ficou profundamente tocada ao assistir. Chorou muito por saudade do pai. Nessa participação inaugural na ilha de edição, decidimos gravar novos depoimentos dela a partir das emoções afloradas pelo filme. Ela também selecionou as falas das nhandesy no material bruto e as traduziu para o português, indicando os depoimentos a serem utilizados. Por fim, opinou sobre as sequências e decidiu pela exclusão de uma cena linda, registro documental da nhandesy Julia e suas netas em momento de troca de cuidados dos cabelos, argumentando que poderia reforçar preconceitos da sociedade local (Ferreira 72).

Nesse trecho em que é descrito o processo cinematográfico, fica insinuado que Rodrigo Arajeju lamenta a exclusão da sequência fílmica julgada como "linda". Entretanto, diante de conflitos sociais e políticos locais, predominam a ausência da cena e a argumentação de Valdelice Veron. Essa negociação desvela os jogos de omissões e revelações, de resistências e de renúncias próprios do gesto tradutório. O cinema posto como um agenciamento político 9 e tradutório será permeado por escolhas poéticas, narrativas, e semióticas que deem conta da complexa tarefa de tradução entre mundos.

No livro "Traduções Canibais: uma poética xamânica do traduzir" (2019), Álvaro Faleiros, dentre outros intuitos, se dedica à análise do "Canto da Castanheira" primeiramente traduzido por Eduardo Viveiros de Castro (1986) e, posteriormente, por Antônio Risério (1993), para, no fim, propor uma retradução. Seu gesto tradutório não se furta de encarar a página em branco como um espaço para encenar a escrita. Entre os recursos utilizados para a

${ }^{9}$ A esse respeito: Rancière, em "A partilha do sensível”, pontua que a estética se alia à política por meio "do recorte sensível do comum da comunidade, das formas de sua visibilidade e de sua disposição" (Rancière 26). É a partir daí podese pensar as intervenções políticas dos artistas. 
reescrita, encontramos epítetos, notas performativas e dois outros tipos de notas, a saber:

alguns breves comentários poéticos sobre o universo simbólico ali envolvido, para tornar menos obscuras algumas metáforas centrais (como, por exemplo, alguns indícios do que está implícito nas metáforas 'ação de emplumar' e de 'ir caçar tucanos'); e alguns outros comentários para marcar os principais movimentos enunciativos do texto, uma vez que, para o leitor não enunciado, os códigos desse regime enunciativo são totalmente desconhecidos (Faleiros 67-68).

Aqui fica evidente o esforço para diminuir distâncias entre os cantos xamânicas orais e performáticos e a escrita poética, assim como fica ressaltada a complexidade imbuída na tradução interontológica.

Diferentemente do trabalho de Faleiros, a tradução entre distintas cosmologias pode culminar, como sabemos, em incompreensões, esteriotipificações e reducionismos. Não são raros os casos em que mitos ameríndios são apequenados e infantilizados ${ }^{10} \mathrm{ou}$, ainda, os casos em que nos filmes se sobressai a imagem do "bom selvagem", do indígena quinhentista ou romântico. O documentário "Tekoha - o som da terra", por sua vez, tem se constituído como uma importante concretização política-poética de outro movimento e de outra narrativa.

\section{A visibilidade da palavra e do silêncio}

O documentário “Os verdadeiros líderes espirituais" (2013, 67min), filmado nas Aldeias Yann Moroti Wherá e Morro dos Valos em Biguaçu - Santa Catarina, é um exemplo daquilo que An-

${ }^{10}$ Mais a esse respeito, consultar o artigo "Línguas ameríndias: modos e caminhos da tradução”, de Bruna Franchetto (2012). 
dré Brasil (Formas do antecampo: performatividade no documentário brasileiro contemporâneo; Ver por meio do invisivel: o cinema como tradução xamânica) vem elaborando como uma marca importante do cinema indígena: o peso do antecampo na constituição da narrativa. Neste documentário, em que especial atenção é dada à espiritualidade guarani e ao conhecimento das plantas medicinais, Alberto Alvares, guarani nhandewa, se apresenta na primeira sequência fílmica e anuncia seus propósitos: preservação do modo de ser guarani (nhande reko) a partir dos conhecimentos do xeramõi Alcindo e xejarji Rosa. Esses percebidos por nós como aquelas "'pessoas coletivas', células que conseguem transmitir através do tempo suas visões sobre o mundo numa resistência continuada" (Krenak 28). No decorrer do longa-metragem, as entrevistas são feitas por Alvares no antecampo, cujas perguntas encontram maior ou menor adesão conforme o caso.

André Brasil e Bernard Belisário no artigo "Desmanchar o cinema: variações do fora de campo em filmes indígenas" (2016) analisam como cinco filmes feito por povos originários no Brasil ${ }^{11}$ se relacionam com o fora de campo (tanto no aspecto fenomenológico, quanto cosmológico). O que está em jogo é a maneira como o campo do visível dialoga com o invisível. Para exemplificar, citamos análise do documentário "Bicicletas de Nhanderu" (2011, 45 min) dirigido por Ariel Ortega e Patrícia Ferreira sobre o cotidiano do povo Mbya-guarani.

\begin{abstract}
O fora de campo permitirá justamente esse duplo e mútuo movimento: de um lado, os personagens deixam a aldeia para viajar pelo entorno (sejam outras aldeias, sejam as fazendas, os municípios vizinhos, os espaços turísticos como as ruínas das Missões Jesuíticas). De outro, esse entorno adentra a vida na aldeia, por meio do comércio miúdo, da festa, do jogo e da bebida, por meio da ameaça invisível dos fazendeiros. Do
\end{abstract}

\footnotetext{
${ }^{11}$ A saber: Curadores da terra-floresta (2013); As hipermulheres (2011); Tatakox da Vila Nova (2009); Shuku Shukuwe: a vida é para sempre (2012) e Bicicletas de Nhanderu (2011)
} 
fora de campo, vêm também os signos do universo mítico e espiritual mbya-guarani (Brasil; Belisário 620).

O fora de campo é ali considerado como aquilo que não pode ser visto em cena, mas que nela pode incidir. No aspecto cosmológico, o fora de campo, nos filmes analisados, está contíguo à aldeia, ora abrigando mundos outros, habitados por animais-espíritos, por agências e potências não humanas da floresta, ora por fazendeiros, por turistas. Em suas palavras: “o fora de campo será justamente o que torna permeável, o que permite a passagem, no filme, entre mundos contíguos mas profundamente díspares, incomensuráveis" (Brasil; Belisário 606).

Se o fora de campo é o conceito mais amplo daquilo que está para além do enquadramento na tela, o antecampo é especificamente o espaço atrás da câmera ${ }^{12}$, que comporta quem decide o que filmar e como. No artigo "Formas do antecampo: performatividade no documentário brasileiro contemporâneo", André Brasil se debruça sobre a tese de que no domínio do documentário há grande espaço para que a performatividade se desdobre no antecampo.

Enquanto na ficção, o antecampo comumente não comparece em diálogo com a cena, constituindo-se como um espaço heterogêneo, de outra natureza; no documentário, estará dialogicamente ligado à cena, imbricado a ela. Quando o diretor ou a equipe de filmagem, que habitam o antecampo, adentram a cena, há uma duplicidade de efeito:

de um lado, estes sujeitos - antes, fora de campo - ficcionalizam-se um pouco, compõem, de um modo ou de outro (mas de dentro), a representação. Por outro lado, a representação é fendida, passa a abrigar, processualmente, uma relação de mútua implicação e alteração entre quem filma e quem é filmado, entre mundo vivido (extradiegético) e mundo fílmico (diegético) (Brasil 2014).

${ }^{12}$ Mais a esse respeito, ver Aumont (2004). 
Se ao trabalhar a mise-en-scène e a montagem, o diretor pode se manter de fora da cena, à explicitação do antecampo permite seu posicionamento interno, exposto à relação com o outro filmado, esta que deve ser elaborada no interior da cena. O modo como o comparecimento ao outro é expresso no filme pode variar do total ocultamento e distanciamento à extrema visibilidade do diretor (e da equipe) em cena, passando por situações em que a presença faz-se audível, mas não visível. Em alguns casos, o antecampo é sugerido menos pela aparição do diretor do que pela maneira como o sujeito filmado devolve o olhar à câmera ou se dirige à equipe tornando presente, quase tangível, aquilo que não é concretamente visível. A explicitação do antecampo participa assim do contínuo abalo do regime representativo clássico, no qual ver significa objetivar (tornar objeto), pressupondo um recuo, um ocultamento do próprio ato de olhar (e do corpo daquele que olha). A exposição do antecampo revela um olhar situado, participante, que sofre, em retorno, os afetos do mundo (Brasil 2014).

No documentário "Os verdadeiros líderes espirituais”, Alberto Alvares ficcionaliza-se ao adentrar a cena, em determinados momentos, mas opta também por tornar-se apenas audível em outros, conduzindo entrevistas por meio de perguntas. Ao revelar equipamentos de filmagem ou a si mesmo, Alvares expõe a linguagem fílmica e o percurso anti-ilusionista.

Em suas reflexões sobre o fazer cinematográfico, Alberto Alvares também chama atenção para o tempo de cada personagem, que deve ser respeitado:

O cinema guarani é diferente do cinema não indígena. Percebo que, em muita das vezes, os trabalhos realizados por não indígenas não respeitam o tempo dos mais velhos. Chegam na aldeia, querem filmar tudo e no final acabam filmando nada. Isso deixa os mais velhos desconfiados, 
eles observam e entendem que os juruá são prisioneiros da teoria e dos pensamentos (Alvares 23-24).

Fica descrita aqui não somente uma crítica ao modo como documentaristas captam imagens dos povos ameríndios, mas também uma afirmação de outro modo de escuta. Segundo Alvares, "a câmera é como se fosse um segundo olho, um segundo ouvido, ela não é apenas uma guardadora de imagem, ela é uma Guardiã da Memória” (Alvares 15).

Delimitados estão, pelo menos, dois motes norteadores do documentário: realizar registros históricos que contribuam para a construção da memória e para o fomento de tradições, por um lado, e, por outro lado, abrir o diálogo com a sociedade não indígena que desconhece sua cosmologia, possibilitando que o cinema funcione como um dispositivo político e tradutório.

Durante todo o documentário, fica descrita a confiança adquirida por Alberto Alvares para a realização do documentário e a percepção de que o cinema pode ser um meio de tradução e divulgação do pensamento indígena. A esse respeito, xeramõi Alcindo e xejarji Rosa afirmam: "Alberto veio de muito longe e não viu muito o costume por onde passou. Por isso temos que dar valor ao seu filme. Só assim os outros vão nos valorizar" (57 min, 2013, grifos nossos).

Relevante descrever o que as palavras "xeramõi" e "xejaryi" carregam consigo para melhor apreender o motivo pelo qual o documentário elege esses personagens como os protagonistas:

Literalmente, xeramoi】 significa "meu avô", mas seu uso remete também à posição do xamã ou, em contextos mais amplos, como na acepção que utilizei acima, é um modo de se referir a um mais velho que se respeita. Seu correlato feminino é xejaryi (minha avó). Tais termos remetem à sobreposição comum entre a posição de liderança dentro um grupo familiar (normalmente exercida por um casal de anciãos que são avós de muitos) e as figuras identificadas 
como xamãs, responsáveis por conduzir os rituais na opy e pelas curas e cuidados exercidos por meio do xamanismo. Há diversos outros termos que reproduzem essa relação de respeito e referência ao xamã guarani, entre eles: karai e kunhã karai; e nhanderu e nhandexy (Keese 48).

Alvares traduz os termos "xeramõi" e "xejaryi" como avô e avó nas legendas em português talvez pela ausência de um léxico melhor, na medida em que falta um vocábulo em nossa língua que desse conta concomitantemente da relação familiar e religiosa que guardam os termos em guarani.

A relação de parentesco dividida por Alvares e os indígenas guarani que compõem o documentário abrem oportunidades que um cineasta não indígena dificilmente alcançaria como pontuamos anteriormente. Entretanto, apesar dessa relação de confiança é possível encontrar certa resistência (ou ainda "esquiva") nas filmagens. A esse respeito, destacamos a sequência na qual xejarji Rosa colhe milho enquanto o cineasta lhe pergunta sobre o canto sagrado do awaxi 'ete' $i$ (verdadeiro milho). Dona Rosa parece resistir à pergunta: sem olhar para a câmera, detém-se e insiste no silêncio a despeito do pedido que cantasse (Imagem 9).

Alvares, revela-se no antecampo, não somente pelas perguntas, mas também exemplificado um trecho do canto que ele conhecia. Xejarji sorri e afirma "Seu avô canta de outro jeito, quando o milho está nascendo", na sequência afirma "Seu avô sabe mais que eu. Eu quase não sei nada”. O filme fica, portanto, sem o canto.

Essa simulação, que descrevemos a partir da cena do canto do milho, manifesta-se em outras esferas da cosmologia guarani, seja na dança, seja na política. Lucas Keese em “A esquiva do xondaro: movimento e ação política entre os Guarani Mbya" discute como a "esquiva", primeiramente, percebida como um movimento constitutivo da dança xondaro ${ }^{13}$ está mais relacionada a ideia de

13 A respeito do movimento da esquiva na dança guarani, ver: "Entre os movimentos, havia inúmeros fingimentos caricatos, ameaças que redundavam em

Cad. Trad., Florianópolis, v. 41, $\mathrm{n}^{0} 2$ p. 328-361, mai-ago, 2021. 
"provocar o erro do adversário" do que ideias como se furtar a algo, fugir, escapar, negligenciar, desviar de uma responsabilidade, como comumente encontra vez na língua portuguesa (Keese 38), posteriormente, desdobra seus sentidos para a percepção de que o movimento da esquiva vai além, pois ajuda a pensar as dinâmicas entre corpos, coletivos e resistências. O pesquisador, então, se debruça na análise da esquiva ou da enganação "como modos políticos de conduzir a incorporação do exterior, transformando posições e relações de poder" (Keese 28).

O uso de enganação como forma de superar adversários mais fortes é central, como vimos, em uma das principais narrativas mitológicas dos Guarani Mbya, a história dos irmãos Sol e Lua. Durante o episódio de vingança contra as onças originárias, Kuaray (Sol), embora divindade, não supera as onças pela força, mas pelo engenho. Primeiro, desafiando- as a entrarem em armadilhas que pareciam inofensivas, mas eram fatais, e, depois, induzindo-as a atravessarem uma ponte apenas para que durante a travessia elas sucumbissem. É importante dizer, lembrando do movimento da enganação como ação política capaz de reorganizar e subverter posições e com isso criar novas possibilidades de existência, que sobrepujar as onças originárias por meio da enganação é um momento crucial para a conformação da terra em que viverá a humanidade (Keese 97).

falhas, quedas, tropeços em si mesmo e outros do tipo. Contudo, essas ações inesperadamente desfaziam-se e os ataques voltavam a demandar esquivas reais, como se fosse uma forma para testar a atenção e a habilidade do oponente sem ter que atacá-lo propriamente e, ao mesmo tempo, uma estratégia para enganá-lo por meio dessas distrações. Uma espécie de jogo nhembotavy, de enganar fazendose de bobo, tal qual a mandiga da capoeira angola, quando o capoeirista, numa ginga de bêbado ou fingindo-se avariado por um golpe do adversário, apenas o distrai, inebriando o rival de humor e/ou presunção, deixando-o despreparado para o movimento que virá" (Keese 57). E ainda: "Seára (2012) obtém de um interlocutor da aldeia Mbiguaçu, em Santa Catarina, uma relação de oito tipos de xondaro (tangará, tupã, djakairá, nhamandu, dos macacos, kutchuva, cobra e kyre’'yロmba)" (Keese 63) 


\section{Figura 9:}

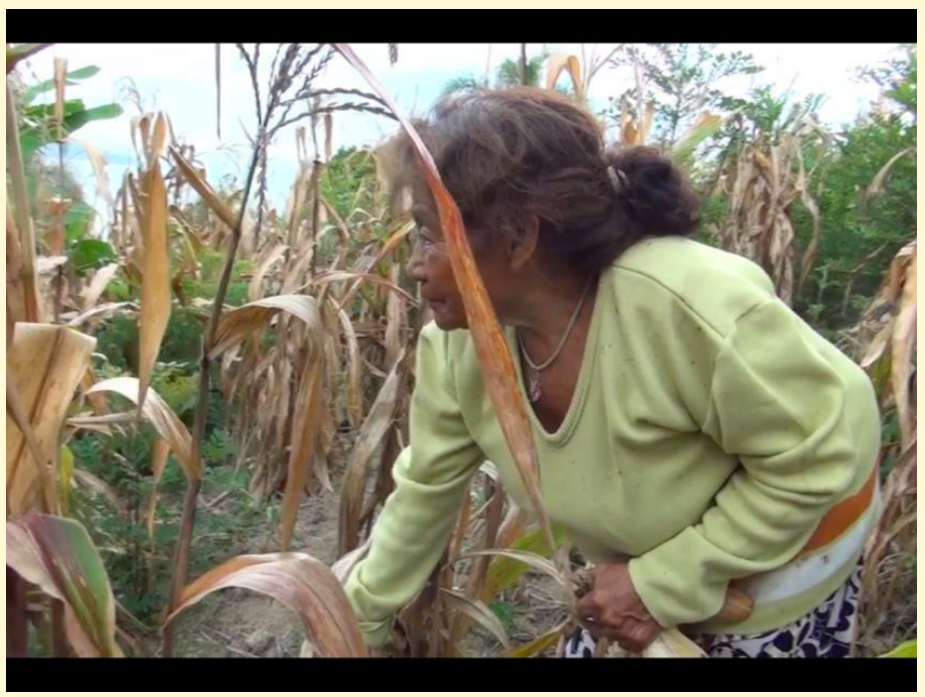

Fonte: Os verdadeiros líderes espirituais, 2013.

Essa reflexão se torna relevante neste artigo na medida em que podemos entender que produzir engano no rival é uma estratégia de luta enraizada no modo de vida guarani e que será utilizada não somente contra adversários, mas também na interação com aquele que traz consigo uma câmera, um gravador.

Ao entoar o canto do milho no antecampo, Alvares compartilha com a xejaryi Rosa o espaço-tempo daquela cena, compartilha em alguma medida uma mise-en-scène a partir do antecampo, distanciando-se da enunciação cinematográfica clássica. Mas, há uma tensão dialógica, porque a despeito da tentativa de aproximação de Alvares, do desejo de captação e descrição, predomina a suspeita a respeito de sua possibilidade ou adequação. A mediação encontra, então, impasses e entraves.

Pierre Clastres sobre sua experiência com o povo guarani descrevia que se os índios consentem muito facilmente em contar seus mitos, "eles recusam, em contrapartida [...] deixar entreouvir o 
menor fragmento do que chama de Belas Palavras, lugar de um saber esotérico [sic] que descreve sucessivamente em uma linguagem de encantamento, a gênese dos deuses, do mundo e dos homens" (Clastres 15).

Egon Shaden, em "Aspectos fundamentais da cultura guarani”, descreve que "o receio de se abusar ou fazer uso inadequado das rezas é um dos motivos da relutância que o pesquisador se depara quando pede que o guarani lhe ensine as que possui ou conhece" (Shaden 119). Os motivos que levaram xejarji Rosa a não cantar diante da câmera poderiam ser lidos a partir de diferentes chaves. Timidez? Receio de errar? Recusa de revelar algo significativo de sua cosmologia? Exemplificação do "formidável muro de silêncio com o qual envolvem o edifício de suas crenças" (Clastres 10)?

Entretanto, mais importante que desvendar tais causas talvez seja mais expressivo pensar em como tal postura foi ressignificada no filme, sendo vista como uma aprendizagem ao modo guarani, uma forma de responder com silêncio. A sequência fílmica do (não) canto do milho poderia ter sido interpretada como a que não funcionou e ter sido excluída na montagem; contudo, ela é mantida e acaba por gerar reflexões. Alvares, em seu trabalho monográfico, afirma "Dona Rosa me ensinou com seu silêncio a importância de se respeitar o tempo e o espaço de cada imagem e que nem sempre o aprendizado acontece através da palavra. Acontece também através do silêncio e da observação" (Alvares 20).

Em outro momento, Alvares corrobora: "optei então por começar pelo silêncio. Escutar o que não me era dito, seguindo o tempo dos pássaros, me via eternizando o tempo, guardando vozes e silêncios, de encontro com a sabedoria das pessoas" (Alvares 25). O silêncio é visto como um ato performativo, esse que se expressa, então, não somente por meio de palavras, mas também com sua ausência.

Apesar de nessa sequência fílmica a esquiva ou o silêncio ter se sobressaído, o documentário também é permeado por diálogos, nos quais mais do que descrever "categorias analíticas" (ou conceitos) do universo guarani, o cineasta Alvares, no fora de campo, 
e o xeremõi Alcindo, em tela, entram num jogo discursivo em que conversando, fazem, performam sua cosmologia. Para ficarmos com o ensinamento de Wittgenstein "a linguagem que usamos está antes de tudo firme e publicamente enraizada no que nós fazemos juntos" (Perloff 224).

É dessa forma que o xeremõi ensina sobre os efeitos medicinais das plantas, revela, por exemplo, os efeitos do araxa contra a pressão desregulada, os efeitos da "aroeira" contra diabete ou ainda o efeito da casca de jaboticaba contra problemas da próstata (Imagem 10).

\section{Figura 10:}

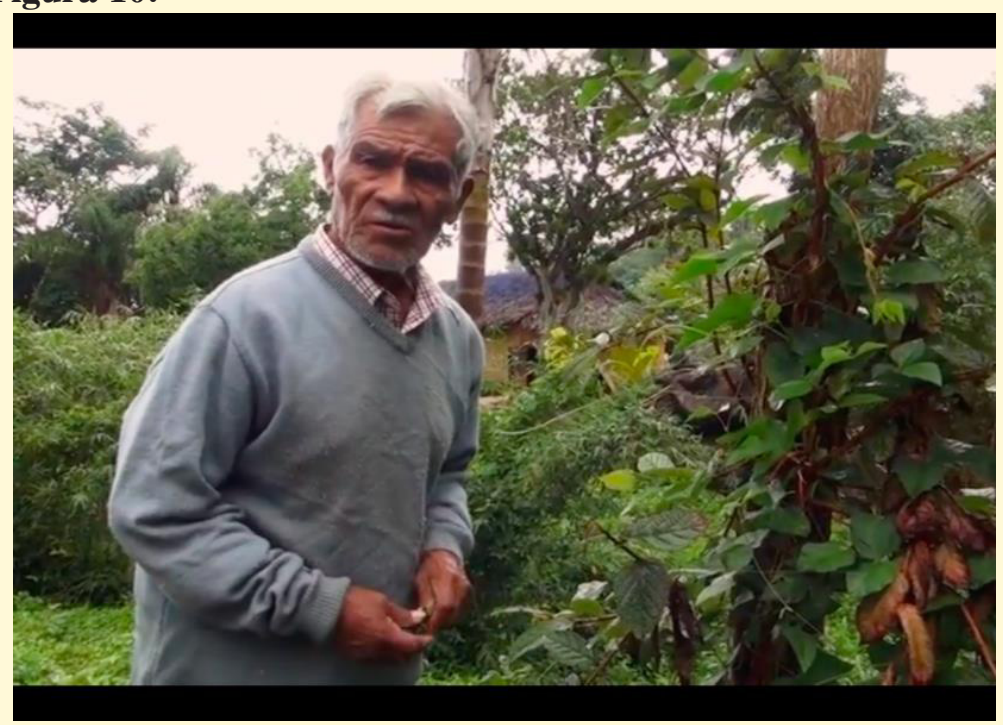

Fonte: Os verdadeiros líderes espirituais, 2013.

Observe que o documentário revela uma postura distinta daquela descrita por Manuela Carneiro da Cunha em "Cultura com aspas". Ali a pesquisadora chama atenção, a partir da discussão do direito de propriedade intelectual "da vacina de sapo" ou kampô entre os yawanawa, os kaxinawa e os katurina, para o extremo sigilo que os conhecimentos tradicionais adquiriram diante dos riscos 
da biopirataria, transformando-se em "segredos de Estado" (Carneiro da Cunha 326). O movimento do documentário, entretanto, é outro. Revela por meio de específica descrição parte de sua "agrobiodiversidade" - ou da "diversidade biológica em variedade de plantas domesticadas" pelos guarani - , exemplificando, por meio do cinema, suas reivindicações quanto ao reconhecimento da medicina indígena. Afirmam seu regime de conhecimento e de cultura.

Cabe lembrar que o documentário é intitulado "Os verdadeiros líderes espirituais" e, como nos ensina Viveiros de Castro (2002), o xamã é o líder espiritual, mas concomitantemente também é o médico, o cientista e o diplomata. Manuela Carneiro da Cunha em "Cultura com aspas" reflete: "Em todo o ocidente amazônico, os xamãs, como se sabe, são os viajantes por excelência [...] sob o efeito do ayahuasca e de outros alucinógenos, os xamãs viram tudo. É por isso que nada os surpreende" (Carneiro da Cunha 108).

Outra sequência fílmica que explicita o labor do xeramõi é a que descreve um jovem cuja doença não fora identificada pela medicina tradicional e que aguarda os processos xamânicos de cura. Nessa sequência, a partir de um diálogo, que passa de hábitos alimentares a crenças ligadas ao destino do homem, pouco a pouco, vai-se construindo a receita médica: folha de mandioca, folhas medicinais, chá.

A neta do xeramõi, que é apresentada algumas cenas antes, adentra o espaço para se integrar ao processo de cura. Enquanto, ela socava e peneirava milho amarelo para fabricação de mbodjape (espécie de pão utilizado no ritual espiritual), afirma "Eu não uso jaleco para fazer a cura. Quando vocês olham para mim, não percebem" para a seguir dizer "Eu aprendi muito sobre remédios, mas ninguém acredita muito em mim".

Quando estamos diante dessa sabedoria, que é adquirida com os mais velhos e também em sonhos, encontramos lugar para uma epistemologia que agrega a experiência ao conhecimento. Ou mais do que isso, o conhecimento não pode se dá separado da experiência. Giorgio Agamben, em "Infância e história”, discorrerá sobre como na Modernidade, desde Descartes (com a máxima ego cogito), passando por Kant, o homem foi "expropriado de sua 
experiência”. Em suas palavras: “O que caracteriza o presente é que toda autoridade tem o seu fundamento 'inexperienciável', e ninguém admitiria aceitar como válida uma autoridade cujo único título de legitimação fosse uma experiência" (Agamben 23). Dessa forma, a ciência moderna nasce de uma desconfiança em relação à experiência como era entendida tradicionalmente.

A comprovação científica da experiência que se efetua no experimento - permitindo traduzir as impressões sensíveis na exatidão de determinações quantitativas e, assim, prever impressões futuras - responde a esta perda de certeza transferindo a experiência o mais completamente possível para fora do homem: aos instrumentos e aos números. mas, deste modo, a experiência tradicional perdia na realidade todo seu valor (Agamben 26).

Contudo, pela cosmologia ameríndia, o saber espiritual e medicinal referenciado como verdadeiro é aquele ligado à experiência, ao místico e ao sonho. Para continuarmos com Agamben, citamos:

Os mohave (nisto não dissipeis das outras cultura xamânicas) creem que os poderes xamânicas e o conhecimento dos mitos, assim como das técnicas e dos cantos a que eles se referem, são adquiridos no sonho. E não só: se viessem a ser adquiridos em estado de vigília, permaneceriam estéreis e ineficazes até que fossem sonhados (Agamben 34).

Destacamos, finalmente, que o espectador adentra a casa de reza, opy mbya, por meio da câmera de Alberto Alvares na última sequência do documentário e pode entrever um ritual guarani. Mas, sobre ele não muito é dito. O espectador pode acompanhar o rito, observando, em meio à escassa iluminação, seus simbolismos: 
o fogo, o canto, a dança, os instrumentos, flores e alimentos estão a compor a casa de reza (Imagens 11 e 12).

Essa é a sequência em que menos encontramos o discurso descritivo, expande-se o movimento do corpo e da espiritualidade. As rezas, então, não são traduzidas. E, como no trecho de "Tekoha - o som da terra", em que não se sabe o que é compartilhado pelas mulheres entre si, o espectador se deterá no canto-dança-reza sem acessar seu significado em palavras.

\section{Figura 11:}

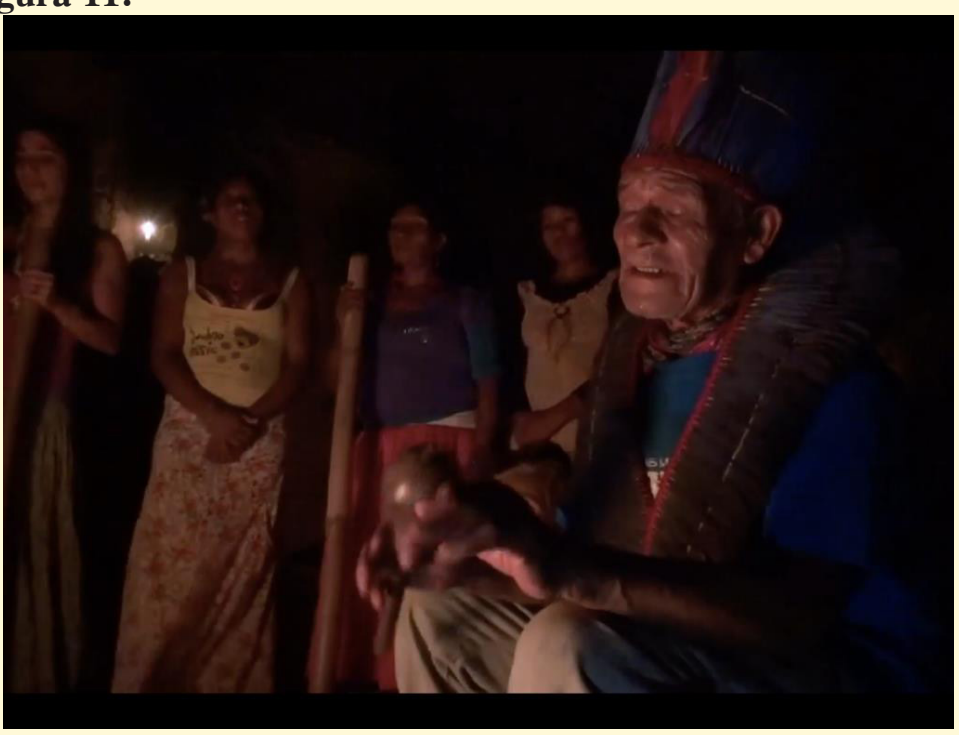

Fonte: Os verdadeiros líderes espirituais, 2013. 


\section{Figura 12:}

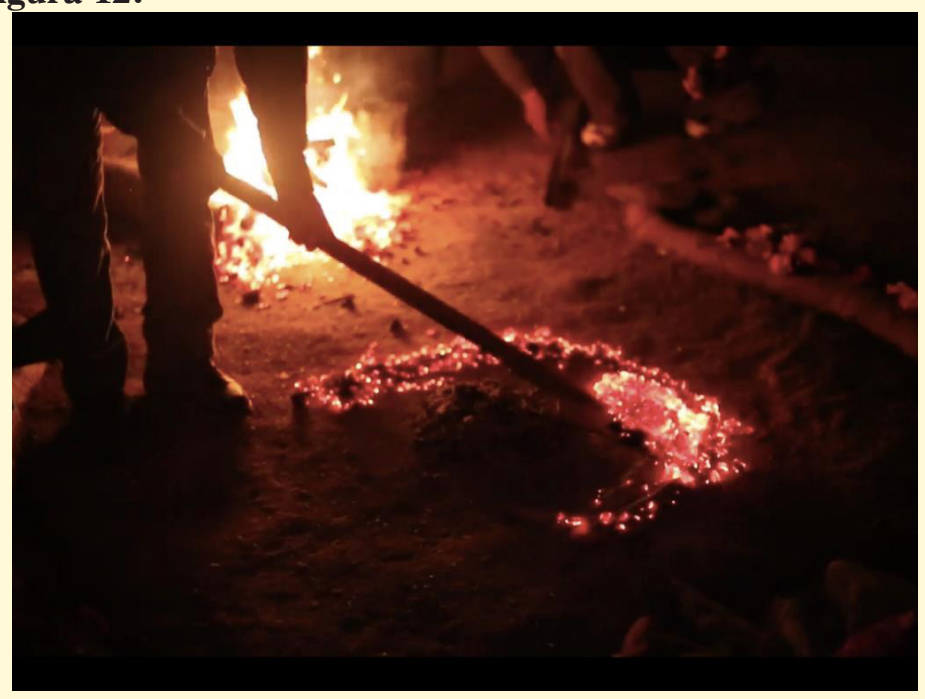

Fonte: Os verdadeiros líderes espirituais, 2013.

Segundo Keese (2017), na opy mbya, a visão não é a que recebe maior valorização, pois os demais sentidos ficariam prejudicados se existissem muitos estímulos visuais. Portanto, encontramos como estética do ritual guarani: a escuridão da opy, o minimalismo de seus artesanatos e a invisibilidade estratégica, na medida em que outros sentidos devem receber maior relevância e não a visão.

É dessa forma que parece ser mais oportuno se aproximar do sagrado, daquilo que é invisível e que constitui a cosmologia guarani. Seja por meio do silêncio, seja por meio da esquiva, revela-se, mas oculta-se.

\section{Considerações Finais}

Este artigo buscou, por meio dos documentários de Rodrigo Arajeju, Valdelice Veron e Alberto Alvares, pensar o audiovisual como uma provocação tradutória, poética e antropológica. Situa- 
mos este trabalho como aquele se interessou pelo "modo de ver do cinema guarani" e por perscrutar como os referidos documentários funcionam em sua linguagem e estratégias cinematográficas e/ou poéticas-narrativas de modo a potencializar uma cosmologia.

\section{Referências}

Aumont, Jacques. "Lumière, 'o último pintor impressionista". $O$ olho interminável, Aumont, Jacques, São Paulo: Cosac Naify, 2004, pp. 26-47.

Agamben. Giorgio. Infância e História. Tradução de Henrique Burigo. Belo Horizonte: Editora UFMG, 2008.

Alvares, Alberto. Da aldeia ao cinema: o encontro da imagem com a história. TCC, UFMG: Belo Horizonte, 2018.

Benjamin, Walter. "A tarefa do tradutor". Clássicos da Teoria da Tradução, Heidermann, Werner. (org.), Florianópolis: UFSC/ Núcleo de Pesquisas em Literatura e Tradução, 2a. Ed, 2010.

Brasil, André. "Formas do antecampo: performatividade no documentário brasileiro contemporâneo". Revista FAMECOS (Online), v. 20, (2013): 578-602.

Brasil, André. "Ver por meio do invisível: o cinema como tradução xamânica". Novos Estudos CEBRAP, v. 3, (2016): 125-146.

Brasil, André; Belisario, Bernard. "Desmanchar o cinema: Variações do fora de campo em filmes indígenas". Revista Sociologia e Antropologia, v. 6, (2016): 601-634.

Clastres, Pierre. A fala sagrada: mitos e cantos sagrados dos índios guarani. Tradução de Nícia Adan Bonatti. SP: Papirus, 1990. 
Carneiro da Cunha, Manuela. Cultura com aspas e outros ensaios. São Paulo: Ubu, 2017.

Faleiros, Álvaro. Traduções Canibais: uma poética xamânica do traduzir. Florianópolis: Cultura e Barbárie, 2019.

Ferreira, Rodrigo Siqueira (Arajeju). TEKOHA - som da terra: a liderança das nhandesy nos processos autogestionários da vida e do território do Povo Kaiowa no Tekoha Takuara. Dissertação. Brasília - DF, 2017.

Franchetto, Bruna. "Línguas ameríndias: modos e caminhos da tradução". Cadernos de Tradução. v. 30, $\mathrm{n}^{0} 2$, (2012): 35-62. Portal de Periódicos da UFSC. 20/05/2012. DOI: https://doi.org/10.5007/2175-7968.2012v2n30p35. Disponível em: https://periodicos.ufsc.br/index.php/traducao/article/view/21757968.2012v2n30p35/23493.

Keese dos Santos, Lucas. A esquiva do xondaro: movimento e ação política entre os Guarani Mbya. Dissertação de Mestrado - Faculdade de Filosofia, Letras e Ciências Humanas da Universidade de São Paulo. Departamento de Antropologia. Área de concentração: Antropologia Social, 2017.

Kopenawa, Davi; Albert, Bruce. A queda do céu. Palavras de um xamã Yanomami. Tradução de Beatriz Perrone-Moisés. São Paulo: Companhia das Letras, 2015.

Krenak, Ailton. Ideias para adiar o fim do mundo. São Paulo: Cia das Letras, 2019.

Perloff, Marjorie. A escada de Wittgenstein: a linguagem poética e o estranhamento do cotidiano. Tradução de Aurora Fornoni Bernardini; Elisabeth Rocha Leite. São Paulo: Ed. da Universidade de São Paulo, 2008.

Plaza, Julio. Tradução Intersemiótica. São Paulo: Perspectiva, 2003.

Rancière, Jacques. A partilha do sensível: estética e política. Tradução de Mônica Costa Neto. SP: Ed. 34, 2015.

Rothenberg, Jerome. Etnopoética no milê'. Azougue, Rio de Janeiro, 2006. 
Shaden, Egon. Aspectos fundamentais da cultura guarani. São Paulo: Ed. da Universidade de São Paulo, 1974.

Viveiros De Castro, Eduardo. A inconstância da alma selvagem. Editora: Cosac Naify, São Paulo, 2002.

Zaffaroni, Eugenio Raúl. La pachamama y el humano / Eugenio Raúl Zaffaroni. Ilustrado por Miguel Rep ; con prólogo de Osvaldo Bayer; con colaboración de Matías Bailone. - 1a ed. - Buenos Aires: Colihue; Ciudad Autónoma de Buenos Aires: Ediciones Madres de Plaza de Mayo, 2011.

\section{Filmografia:}

As hipermulheres (Itaõ Kuẽgü). (MT, 2011, 80 min). Direção: Takumã Kuikuro, Carlos Fausto e Leonardo Sette. Aldeia Kuikuro de Ipatse. Vídeo nas Aldeias.

Bicicletas de Nhanderu. (RS, 2011,46 min). Direção: Ariel Ortega. Realização e imagens: Coletivo Mbya-Guarani de Cinema. Aldeia Koenju. Vídeo nas Aldeias.

Curadores da terra-floresta (Urihi Haromatimapë). (RR, 2013, 60 min). Direção e fotografia: Morzaniel Iramari Yanomami. Aldeia Watoriki. Hutuka/ISA/UFMG.

Índio cidadão? (DF, 2014, 52 min.), Rodrigo Arajeju. Disponível em link privativo: <https://vimeo.com/116678358> (senha: kayowa). Acesso em: 26/04/2017.

Índios no Poder (DF, 2015, 21 min.), Rodrigo Arajeju. Disponível em link privativo: <https://vimeo.com/161381397> (senha: JURUNApresidente). Acesso em: 26/04/2017.

Karai ha'egui Kunhã Karai 'ete. Os verdadeiros líderes espirituais. (MG, 2013, $67 \mathrm{~min}$ ) - Projeto financiado pela CAPES - OEEI_Observatório da Educação Escolar Indígena - FAE/ UFMG. Disponível em: https://www.youtube.com/ watch? $\mathrm{v}=$ mpNAxnL45UM. 
Shuku Shukuwe: a vida é para sempre. (AC, 2012, 43 min). Realização: Agostinho Manduca Mateus Kaxinawá et al. Aldeia Huni Kuĩ São Joaquim Centro de Memória. Leteraterras/UFMG e Associação Filmes de Quintal.

Tatakox da Vila Nova. (MG, 2009, 23 min). Direção: Guigui Maxakali. Aldeia Vila Nova do Pradinho. Vídeo nas Aldeias.

TEKOHA - som da terra (DF/MS, 2017, 20 min.), Rodrigo Arajeju e Valdelice Veron. Disponível em link privativo: < https://vimeo.com/217334549> (senha: TEKOHA).

Recebido em: 20/11/2020

Aceito em: 31/03/2021

Publicado em maio de 2021

Sabrina Alvernaz Silva Cabral. E-mail: sabrinaalvernaz@yahoo.com.br. ORCID: https://orcid.org/0000-0002-6244-1499.

Sérgio Luiz Rodrigues Medeiros. E-mail: medeirosrodriguessergio@gmail.com. ORCID: https://orcid.org/0000-0003-4263-7942. 